\title{
INTERAÇÕES VIRTUAIS INOVADORAS ENTRE DOCENTES E ESTUDANTES: EDUCAÇÃO A DISTÂNCIA E AFETIVIDADE
}

\author{
SÃO PAULO/SP JULHO/2018
}

\author{
Guilherme William Udo Santos - UNIFACS - guilherme.santos@eadlaureate.com.br \\ Karin Gerlach Dietz - FMU - karin.dietz@eadlaureate.com.br \\ Mírian Queiroz Souza Daniel - UNIFACS - mirian.souza@eadlaureate.com.br \\ Patrícia Aparecida do Amparo - UNP - patricia.amparo@eadlaureate.com.br
}

Tipo: Investigação Científica (IC)

Natureza: Descrição de Projeto em Andamento

Categoria: Métodos e Tecnologias

Setor Educacional: EDUCAÇÃO SUPERIOR

\begin{abstract}
RESUMO
O presente trabalho tem como objetivo apresentar uma pesquisa em andamento que analisa a relação docente-discente em cursos superiores de educação a distância (EAD), a fim de indicar práticas inovadoras que envolvam afetividade. Como objetivos específicos apresentam-se: clarificar como os docentes significam a afetividade no EAD; identificar o que limita a afetividade na relação docente-discente e quais estratégias são adotadas pelos docentes que classificam como afetivas. $O$ problema de pesquisa será constituído por meio das contribuições teóricas advindas da didática e da psicologia histórico-cultural. Desse modo, partimos do suposto que apesar das especificidades do trabalho pedagógico no espaço virtual, como sustenta Philippe Perrenoud, na relação docente-discente sempre estão envolvidas trocas e intercâmbios entre os dois - sejam orais ou escritos. Tais interações envolvem a afetividade, aspecto significativo da relação educacional, presente em todos os momentos, movimentos e circunstâncias das ações humanas. A afetividade, segundo Wallon, é um dos constructos que explicam o psiquismo e atua, juntamente com o ato motor e a cognição, no processo de desenvolvimento e construção do conhecimento. A afetividade, especificadamente, é um conjunto de funções responsáveis pelas emoções, sentimentos e paixão. Refere-se à capacidade do ser humano de ser afetado, inclusive fisiologicamente, positiva ou negativamente. Essas implicações teóricas são investigadas por meio de uma pesquisa de abordagem quanti-qualitativa concretizada em questionário e entrevistas. O questionário foi respondido por 16 docentes de licenciatura. Após aplicação do questionário, serão selecionados docentes a serem entrevistados. As entrevistas serão audiogravadas, transcritas e analisadas a fim de se atingir o objetivo proposto. Por meio desta pesquisa, pretende-se indicar possibilidades de práticas pedagógicas inovadoras que considerem a afetividade na educação a distância.
\end{abstract}

Palavras-chave: educação a distância, inovação, afetividade, ensino superior.

\section{AGRADECIMENTOS}

AOS COLEGAS DOCENTES QUE, ALÉM DA DEDICAÇÃO DIÁRIA AOS DISCENTES E À CONSTRUÇÃO DO CONHECIMENTO, DEDICARAM ALGUNS MOMENTOS DO SEU TEMPO PARA RESPONDER AO QUESTIONÁRIO PROPOSTO POR ESSA PESQUISA. 


\section{Introdução}

Pode-se definir afetividade, segundo o dicionário Houaiss, com as seguintes acepções "qualidade ou caráter de quem é afetivo; conjunto de fenômenos psíquicos que são experimentados e vivenciados na forma de emoções e de sentimentos; tendência ou capacidade individual de reagir facilmente aos sentimentos e emoções" (AFETIVIDADE, 2018). Já Hack e Albuquerque (2016), em estudo sobre a afetividade na educação a distância, analisam a relação estabelecida entre tutores presenciais, tutores a distância e estudantes do Curso de Letras-Português na modalidade EAD e averiguaram que para os sujeitos pesquisados, a afetividade é considerada fundamental para o processo de ensino-aprendizagem, sendo Mensagem via Ambiente Virtual de Aprendizagem o meio mais utilizado nesta relação, além de encontros face a face com tutores presenciais. Além deles, listam-se: Fórum, Chat, Videoconferência, e-mail, Skype, Facebook e telefone.

Os autores também apontam que as interações interpessoais podem estar atreladas tanto a características benéficas da construção de vínculos afetivos quanto prejudiciais. Daquelas citadas como positivas, estão: estímulo à aprendizagem do conteúdo, demonstrar interesse, respeitar as individualidades, mostrar-se empático, ser cuidadoso. Enfatizam também a importância de se dar um rápido feedback aos estudantes, com conteúdo preciso e honesto. Dentre as prejudiciais, os participantes mencionaram: proximidade excessiva que transcende o processo educativo, manifestações de opiniões irrelevantes e mecanicidade das interações.

Silva, Shitsuka e Paschoal (2015) também analisaram a afetividade constituída em torno da educação a distância, no entanto, tiveram como sujeitos de pesquisa 76 estudantes. Os autores consideram que, na perspectiva dos participantes, a interação estabelecida no ambiente virtual é facilitada, pois os estudantes se sentem com maior liberdade para tirar dúvidas, isto é, sentem-se menos inibidos.

Ainda com o objetivo de analisar o papel da afetividade na educação a distância, Campos, Melo e Rodrigues (2014), em uma unidade de pós-graduação a distância entrevistaram 20 pessoas, sendo quatro tutores e dezesseis estudantes. Relatam que 0 termo afetividade se relaciona com as palavras simpatia, empatia e relação harmoniosa, assim como respeito e ajuda em momentos difíceis e comprometimento. Os autores concluem que é impossível, no processo de ensino-aprendizagem, separar efetividade de afetividade, sendo importante o incentivo do tutor durante o curso, elevando o potencial de cada estudante. 
Por meio do levantamento desses estudos correlatos, este trabalho apresenta como objetivo: analisar a relação docente-discente em cursos superiores de ensino a distância, a fim de indicar práticas inovadoras que envolvam afetividade. A seguir, será apresentado o referencial teórico adotado na pesquisa e seus procedimentos metodológicos.

\section{Referencial teórico}

Quando tomamos a afetividade e as práticas inovadoras em EAD como objeto de investigação, estamos explorando aspecto central ao trabalho pedagógico. De acordo com Philippe Perrenoud (1995), as interações estabelecidas entre os professores e os estudantes são estruturantes dos processos de ensino-aprendizagem, possibilitando situações de aprendizagem ou mesmo de distanciamento com relação à escolarização. Torna-se evidente, desse modo, que o tipo de vínculo estabelecido entre docentes e discentes é importante para que se compreendam as especificidades do trabalho pedagógico. Nesse sentido, a afetividade é aspecto significativo da formação, pois ela nos auxilia a compreender o modo como os estudantes são afetados pelas práticas educativas que vivenciam.

Encontra-se nos estudos de Wallon (1879-1962), filósofo e médico francês, contribuições para o entendimento do desenvolvimento humano e do processo educacional. O autor enfatiza, em sua obra, o papel da afetividade na constituição da pessoa. A afetividade, juntamente com os conjuntos funcionais motor, cognição e pessoa, seria essencial no processo de desenvolvimento e construção do conhecimento. De acordo com Mahoney (2004), "é no entrelaçamento com o motor e o cognitivo que o afetivo proporciona a constituição de valores, vontade, interesses, necessidades, motivações que dirigirão escolhas, decisões ao longo da vida" (p. 18).

Segundo a teoria walloniana, o conjunto afetivo oferece as funções responsáveis pelas emoções, paixões e sentimentos, "que são sinalizadores de como o ser humano é afetado pelo mundo interno e externo" (MAHONEY, 2004, p. 17). A emoção, para Mahoney e Almeida (2005), seria a exteriorização da afetividade, isto é, a sua expressão motora e corporal e aparece desde os primeiros dias de vida. Para as autoras, "das oscilações viscerais e musculares vão se diferenciando as emoções: medo, alegria, raiva, ciúme, tristeza" (p.20). O sentimento "corresponde à expressão representacional da afetividade. Não implica reações instantâneas e diretas como na emoção" (p.21). Já a paixão, "revela o aparecimento do autocontrole para dominar uma situação" (p. 21). 
qual passa o sujeito. Até o primeiro ano de vida, a criança realiza movimentos desordenados para expressar a afetividade. O processo de ensino-aprendizagem, nesta fase, exige contato, fusão. Do primeiro ao terceiro ano de vida, este processo de modifica: o professor precisa passar a oferecer diversidade de situações e espaços, facilitando a diferenciação em relação aos objetos. Dos três aos seis anos, é preciso reconhecer e respeitar as diferenças. "O tipo de afetividade que facilita essas aprendizagens comporta oportunidades variadas de convivência com outras crianças de idades diferentes e aceitação dos comportamentos de negação" (MAHONEY; ALMEIDA, 2005, p. 23). Dos seis aos onze anos, o predomínio é da razão e a aprendizagem se faz pela descoberta de semelhanças e diferenças entre ideias, objetos e imagens. Dos onze anos em diante, "o processo ensino-aprendizagem facilitador do ponto de vista afetivo é aquele que permite a expressão e discussão [das] diferenças [entre ideias, sentimentos, valores próprios e do outro] e que elas sejam levadas em consideração" (MAHONEY; ALMEIDA, 2005, p. 23).

Assim, as formas de interação e sua qualidade vão sendo ressignificadas pela pessoa ao longo do tempo. Por exemplo, crianças de sete anos ainda têm forte dependência em relação ao adulto, relação que se modifica com a passagem da adolescência e chegada da vida adulta. Manifestações epidérmicas são substituídas por outras exigências afetivas, como necessidade de atenção e a necessidade de respeito e justiça. Em função disso, "perceber e compreender essas mudanças representam um caminho eficiente para resolver boa parte dos conflitos que surgem na relação eu-outro" (DÉR, 2004, p. 75)

Mahoney e Almeida (2005) pontuam que a colocação de limites também é uma expressão da afetividade, necessária em qualquer fase de desenvolvimento do sujeito. Nesta perspectiva, cabe ao professor conhecer a trajetória do estudante, adequando seu ensino às diferentes necessidades afetivas, que são mutáveis ao longo do desenvolvimento do sujeito e também se modificam de pessoa para pessoa. Como pontua Wallon (1975, p. 224), "[o professor] deve, desta maneira, ser uma perpétua remodelação de ideias: deve modificar as suas próprias ideias pelo contato permanente com uma realidade que é móvel, feita da existência de todos e que deve tender para o interesse de todos".

Mas e o estudante adulto? Como se dá a relação afetiva? Nesta fase, conforme pontuam Mahoney e Almeida (2005), o sujeito conhece melhor seus limites, suas possibilidades, pontos fracos e fortes, seus sentimentos e valores, mostrando melhores condições para acolhimento e receptividade de seus pares. A partir desse referencial teórico, articulado com o processo de ensino-aprendizagem, pretende-se analisar a 
relação docente-discente em cursos superiores de ensino a distância, a fim de indicar práticas inovadoras que envolvam afetividade.

\section{Procedimentos metodológicos}

Os objetivos do trabalho serão atingidos por meio de uma pesquisa de abordagem mista, "podendo o estudo quantitativo gerar questões para serem aprofundadas qualitativamente, e vice versa" (MINAYO; SANCHES, 1993, p. 247). A opção pela pesquisa resultou na possibilidade de identificar e analisar informações referentes ao processo de afetividade no EAD. Sendo assim, aplicou-se um questionário a 16 docentes de licenciatura que exercem a sua função no EAD como pré-teste. Esse questionário possibilitou, inicialmente, a compreensão de dados referentes à formação, tempo de exercício profissional, vantagens e desvantagens de plataformas EAD que já utilizou e identificação das dimensões afetivas em sua atividade. Os dados foram tabulados. Também foi utilizado um gráfico digital que mostra o grau de frequência das palavras em um texto (nuvem de palavras), a fim de verificar o campo semântico do termo afetividade e afetividade no processo de ensino-aprendizagem, em específico, no EAD, no trabalho completo, pretende-se utilizar o interpretativismo para análise dos dados.

O questionário aplicado no pré-teste era composto das seguintes questões:

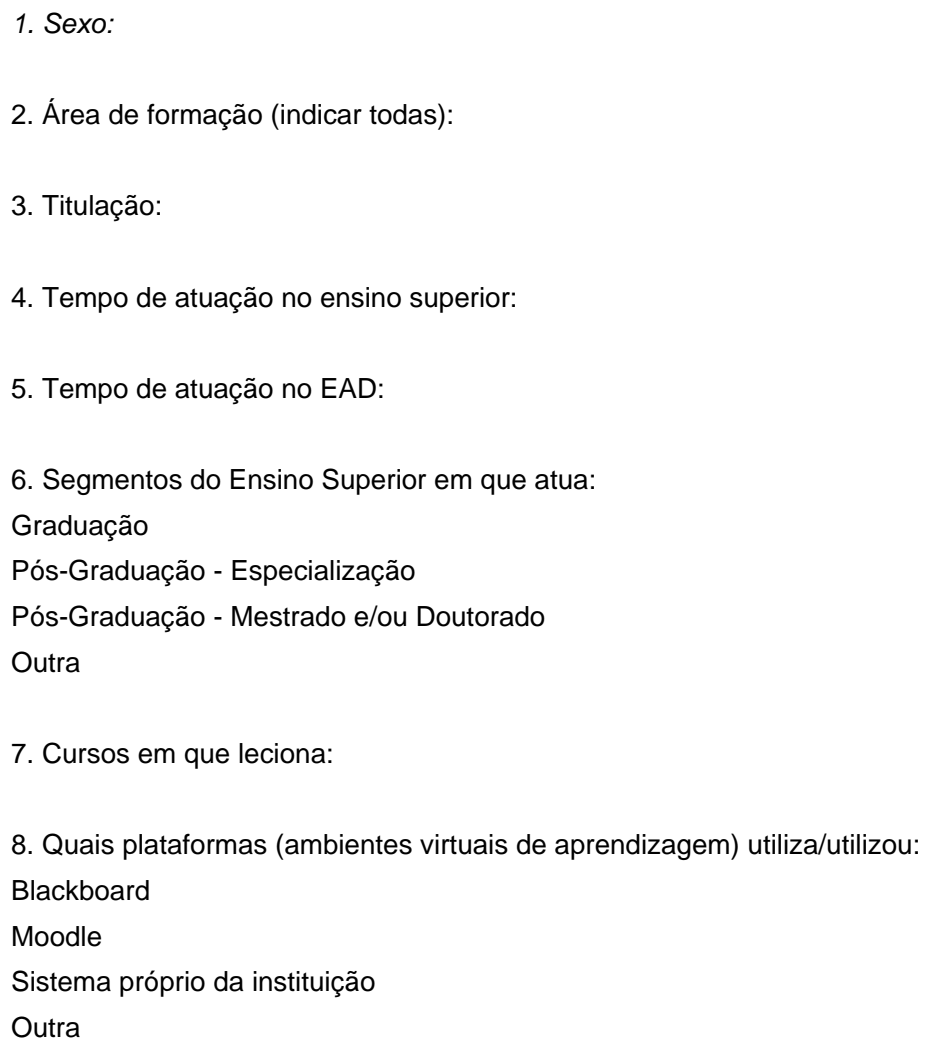


9. Cite as vantagens da(s) plataforma(s) em que atua/atuou:

10. Cite as desvantagens da(s) plataforma(s) em que atua/atuou:

11. Quais canais de interação docente-discente as instituições utilizam/utilizavam?

Fórum

E-mail

Mensagem privada pelo ambiente virtual

Telefone

Aplicativo de celular

Facebook

WhatsApp

Outra

12. Os canais utilizados são suficientes para a interação que gostaria de estabelecer?

13. Se não, quais seriam suas sugestões de mudança?

14. Quais palavras você relaciona à afetividade? Cite ao menos cinco (em ordem crescente de relação).

15. Quais palavras você relaciona à afetividade no EAD? Cite ao menos três (em ordem crescente de relação).

16. Você credita práticas de sucesso no EAD à afetividade? Qual prática de sucesso poderia descrever realizada por você?

17. Há limites na prática afetuosa estabelecida na relação docente-discente? Quais?

18. Existem formas de superar os limites apontados na questão anterior? Quais?

O universo total da pesquisa deverá abarcar, ao menos, 200 docentes para responderem o questionário proposto. Buscar-se-á realizar entrevistas com 50 docentes que serão selecionados a partir da resposta apresentada no questionário. Pretende-se, dessa forma, compreender, a partir desta amostra, se há possibilidades para o exercício de uma prática afetiva nas interações entre docentes e discentes no espaço de aprendizagem virtual e como ela é feita. As entrevistas serão audiogravadas, transcritas e analisadas a fim de se atingir o objetivo proposto.

A sistematização e análise das entrevistas serão pautadas na proposta dos núcleos de significação (AGUIAR; OZELLA, 2013), no intuito de conseguir, paulatinamente, uma maior aproximação das zonas de sentido. Dessa forma, após a transcrição das entrevistas, três etapas devem ser cumpridas para se chegar aos núcleos de significação: 1) Realização de diversas leituras do material para, em seguida, identificar os chamados pré-indicadores, ou seja, temas variados, que se tornam importantes na medida em que são mencionados; 2) Processo de aglutinação dos pré-indicadores, pautada por semelhanças, contradição ou complementariedades, formando, assim, indicadores; 3) Com base nos indicadores, inicia-se uma nova aglutinação, pautada pelos mesmos princípios, em um processo que possibilitará a organização dos núcleos 
de significação.

\section{Apresentação e breve discussão dos resultados do pré-teste}

Em relação aos participantes da pesquisa realizada em pré-teste, cinco são do sexo masculino e onze do sexo feminino. Dos homens, quatro são mestres e um é doutor. Das mulheres, oito são mestras, uma é especialista e duas são doutoras. O tempo de atuação na docência varia. Há aqueles que atuam há 30 anos e outros que iniciaram sua carreira na docência há quatro meses, juntamente com a atuação no EAD, representando um universo novo de professores que já iniciam seus trabalhos em ambientes virtuais. Dos 16 participantes, nove lecionam na graduação e pós-graduação e sete apenas na graduação. Todos fazem uso do Blackboard como ambiente virtual de interação. Nove também se utilizam do Moodle. Sobre o ambiente de aprendizagem, em específico o Blackboard, os docentes listaram algumas desvantagens no seu uso, como recursos limitados, referentes, por exemplo, às possibilidades de correção das atividades, interação entre estudantes e entre estudantes e docente, padrão estético formal, de difícil navegação e pouco intuitivo.

Dos canais de comunicação utilizados na interação com dos discentes, 12 listaram o Fórum de discussão, ambiente de interação aberto para todos os discentes, como principal meio utilizado de troca de mensagens e sete docentes fazem uso de mensagens privadas enviadas por meio do ambiente de aprendizagem. Três docentes responderam que os canais de comunicação não são suficientes para a interação estabelecida com os estudantes e indicam canais específicos de comunicação, como WhatsApp Web, Webconferência, articulação com redes sociais e encontros fora do ambiente virtual.

Um dos participantes, enfatiza que a limitação afetiva estabelecida pelo EAD esbarra na grande quantidade de estudantes que tem por disciplina, impossibilitando "traçar um canal de afetividade e atenção total às respostas e interações" (sic). Outro participante pontua: "[...] deve-se ter cuidado para não confundir laços afetivos familiares e amorosos. A distância emocional deve ser mantida" (sic). Outra fala de um dos participantes a ser destacada é: "A afetividade não deve ultrapassar o respeito e virar intimidade. Pessoas íntimas tendem a 'achar' que tudo pode se dar um 'jeitinho', pois são íntimos" (sic). Tres participantes consideram que não há limites na relação afetiva estabelecida com os estudantes. Um deles pontua e complementa sua resposta: "Na realidade, não acredito que exista um limite para o modo como as pessoas se afetam entre si e como o mundo às afeta". 
Na imagem a seguir, apresenta-se o campo semântico que os pesquisados têm como referencial ao serem questionados sobre o que é a afetividade:

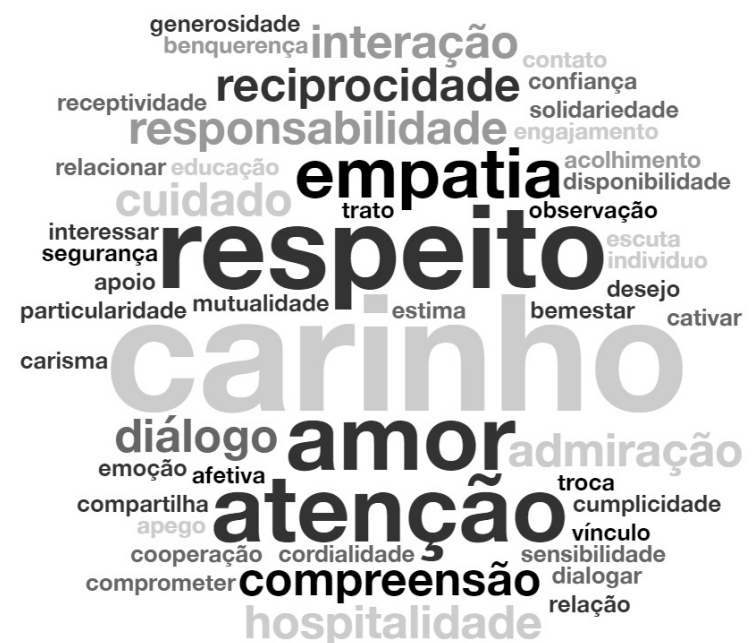

Pode-se perceber o destaque dado às palavras CARINHO, RESPEITO, ATENÇÃO e AMOR. Desta maneira, percebe-se que a relação afetiva para o campo pesquisado é de referencial positivo e muito relacionado ao tratamento dado em relações amigáveis.

Já no quadro abaixo, apresenta-se o campo semântico quando os pesquisados foram questionados sobre afetividade e EAD.

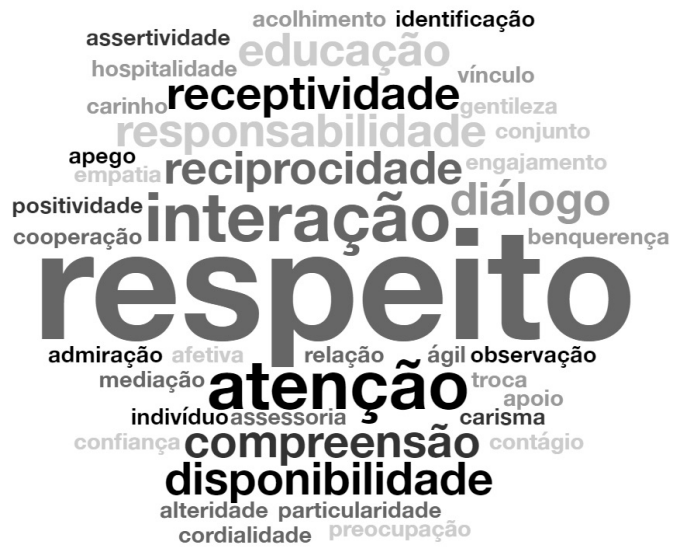

Percebe-se um grande apreço pela palavra RESPEITO. Em uma análise inicial, podemos inferir que muitos atribuem ao respeito as boas práticas interativas em ambientes virtuais de interatividade. Ao relacionar à sala de aula tradicional, percebe-se que nesse aspecto nada difere, uma vez que o respeito na relação docente-discente é primordial para o bom andamento das atividades. Chama a atenção também as palavras ATENÇÃO e INTERAÇÃO, já que ambas são referências às práticas que fazem com que o EAD seja mais próximo das relações presenciais, uma vez que os alunos precisam interagir com seus docentes e tutores, que por sua vez precisam dar a atenção 
devida, de forma que o conhecimento possa ser construído e a relação seja proveitosa para ambas as partes.

Entre as possibilidades registradas pelos sujeitos como passíveis de superar os limites na prática afetuosa estabelecida na relação docente-discente, destacam-se as seguintes para uma futura entrevista a fim de entender melhor a relação afetiva dentro do processo:

\footnotetext{
"Seria importante romper a hierarquia que existe entre o estudante e o professor. O professor é muitas vezes tratado como o detentor dos saberes e o estudante como alguém que deveria recebê-los" (sic).

"A forma é através de mensagens com conotação de compreensão e gentileza" (sic).

"Acredito que não seja interessante [superar os limites na prática afetuosa], visto que tratamos de relações acadêmicas, tanto no EAD quanto no ensino presencial. É fundamental mantermos "alguma distância" nas relações interpessoais" (sic).
}

Por meio das entrevistas a serem realizadas, pretende-se identificar como os docentes pensam que seria possível, por meio dos ambientes de aprendizagem virtual, romper, por exemplo, com as hierarquias e replicar mensagens que possibilitem uma interpretação que denote compreensão e gentileza. Pretende-se também entender porque alguns docentes não objetivam superar as barreiras existentes na relação com os discentes em relação à afetividade.

\section{Referências}

AFETIVIDADE. Dicionário Houaiss, 20 mai 2018. Disponível em . Acesso em 20 mai. 2018.

AGUIAR, Wanda Maria Junqueira de; OZELLA, Sérgio. Apreensão dos sentidos: aprimorando a proposta dos núcleos de significação. R. bras. Est. pedag., Brasília, v. 94, n. 236, p.299-322, 2013.

CAMPOS, Ilka Maria Soares; MELO, Márcia Sandra Meireles de; RODRIGUES, Joventina Firmino. Educação a distância: o desafio da afetividade na percepção de tutores e alunos. In: Anais... 20ํㅡㄹ congresso internacional ABED de educação a distância. Curitiba. p.1-10, 2014.

DÉR, Leila Christina Simões. A constituição da pessoa: dimensão afetiva. In: MAHONEY, Abigail Alvarenga; ALMEIDA, Laurinda Ramalho de. A constituição da pessoa na proposta de Henri Wallon. São Paulo: Loyola, 2004. p. 61-75. 
a distância: um estudo de caso sobre o curso de Letras-Português na modalidade a distância da UFSC. Revista Educação e Linguagens, Campo Mourão, v. 5, n.9, jul-dez, 2016.

MAHONEY, Abigail Alvarenga. A constituição da pessoa: desenvolvimento e aprendizagem. In: MAHONEY, Abigail Alvarenga; ALMEIDA, Laurinda Ramalho de. A constituição da pessoa na proposta de Henri Wallon. São Paulo: Loyola, 2004. p. 13-24.

MAHONEY, Abigail Alvarenga; ALMEIDA, Laurinda Ramalho de. Afetividade e processo ensino-aprendizagem: contribuições de Henri Wallon. Psic. da Ed., São Paulo, p. 11-30, 2005.

MINAYO, Maria Cecília; SANCHES, Odécio. Quantitativo-qualitativo: oposição ou complementaridade? Cad. Saúde Públ., Rio de Janeiro, v.9, n.3, p.239-262, jul/sep, 1993.

PERRENOUD, Philippe. O ofício de aluno e o sentido do trabalho escolar. Porto: Porto Editora, 1995.

SILVA, Priscilla Chantal Duarte; SHITSUKA, Ricardo; PASCHOAL, Patrícia Aparecida Gomes. Afetividade nas interações em AVA: um estudo sobre a interação na educação a distância. Revista Brasileira de Aprendizagem Aberta e a Distância, v.14, p. 11-20, 2015.

WALLON, Henri. Psicologia e educação da infância. Lisboa: Editora Estampa, 1975. 